\title{
Perceptual Load and Sex-Specific Personality Traits
}

\section{The Impact of the Big Five Personality Dimensions and the Autism Quotient on Visual Search}

\author{
Christiane Lange-Küttner'®i and Andrei-Alexandru Puiu² \\ 'Department of Psychology, Bremen University, Germany \\ 2Department of Psychiatry, Psychotherapy and Psychosomatics, Faculty of Medicine, RWTH Aachen University, Germany
}

\begin{abstract}
The impact of sex-specific personality traits has often been investigated for visuospatial tasks such as mental rotation, but less is known about the influence of personality traits on visual search. We investigated whether the Big Five personality traits Extroversion (E), Openness (O), Agreeableness (A), Conscientiousness (C), and Neuroticism (N) and the Autism Quotient (AQ) influence visual search in a sample of $N=65$ men and women. In three experiments, we varied stimulus complexity and predictability. As expected, latencies were longer when the target was absent. Pop-out search was faster than conjunction search. A large number of distracters slowed down reaction times (RTs). When stimulus complexity was not predictable in Experiment 3, this reduced search accuracy by about half. As could be predicted based on previous research on long RT tails, conjunction search in target absent trials revealed the impact of personality traits. The RT effect in visual search of the accelerating "less social" $A Q$ score was specific to men, while the effects of the "more social" decelerating Big Five Inventory factors agreeableness and conscientiousness were specific to women. Thus, sex-specific personality traits could explain decision-making thresholds, while visual stimulus complexity yielded an impact of the classic personality traits neuroticism and extroversion.
\end{abstract}

Keywords: visual search, Big Five Personality Inventory, stimulus complexity, stimulus predictability

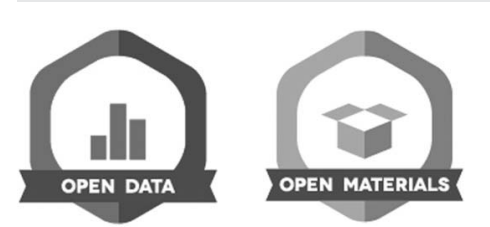

The visual search paradigm usually involves finding the odd-one-out in a group of items in a visual array. The visual search is usually easier, the more unique this odd-one-out item is (pop-out search) and the fewer item features are shared with the distracters (conjunction search; Wolfe, 1994). Items in a visual search array can be in a wrong place violating expectations or even placement rules (Bertrand \& Thullier, 2009; Lange-Küttner \& Bosco, 2016). Their places may be looked at again and revisited (Peterson et al., 2001) if individuals feel unsure. Moreover, in arrays where there is no odd-one-out item, participants usually take more time than when a target is present to make sure they do not miss it (Wolfe \& Van Wert, 2010). Personality traits may influence visual search as nervousness may lead to abolish search fast when the target cannot be readily found (Donnelly et al., 2010). We were interested in finding out whether the personality traits of the Big Five Personality Inventory (BFI), namely neuroticism, extroversion, agreeableness, openness to experience, and conscientiousness as well as autistic traits (AQ) would have such an impact on visual search.

There is some evidence that personality traits can help or hinder one's performance in visual search. For instance, in a visual search task with letters, extroversion was associated with short reaction times (RTs), while neurotic personalities were slower in their visual search (Newton et al., 1992). Yet another study with young adults at university found that low extroversion was the only Big Five personality trait that predicted better accuracy but longer RTs (Peltier \& Becker, 2017). They showed that for rare targets, this personality factor was as important as visual working memory capacity and the ability to inhibit of invalid cues. Thus, previous research did find that especially neuroticism and extroversion appear to have an impact on visual search.

Visual search activity heavily relies on situational awareness (Endsley \& Garland, 2000), which can differ between men and women. Men decided having seen visual search displays before by making quick global decisions but risking false positives, while women's decisions were more circumspect and referred to the distance between the actual items in the display (Brandner, 2007). In a reallife visual search scenario, sex differences were observed 
in gaze patterns before and during street crossing (Tom \& Granié, 2011). Men were more on their guard than women and watched moving vehicles even if there was a street signal available. However, they were also more likely to cross the road while the red signal was on, which suggests that conscientiousness may be less important for men than for women. Nevertheless, these men were also more often found to be running fast across a cross-road than women. Likewise, in a laboratory visual search task, men were faster and more correct than women when a target was present (English et al., 2021).

In the current study, we varied the perceptual load (Lavie, 1995) with regard to set size and visual complexity as both these factors may be responsible for the impact that different personality traits might have on visual search. Many previous studies used visually complex alphabetical letters for search arrays, for instance, Ls and Ts (e.g., Biggs et al., 2017; Peltier \& Becker, 2017), or the visually less complex singletons (Kiss \& Eimer, 2011; Nowakowska et al., 2017; Wolfe et al., 2003) to test item characteristics such as color or size.

We presented young adults with a series of three visual search experiments. The first experiment presented singletons, the second increased stimulus complexity, and the third experiment decreased stimulus predictability, that is, participants could not predict whether the next display would consist of singletons or complex stimuli: Experiment 1 had only one-dimensional unicolored stimuli while in Experiment 2, we increased the visual complexity of the items, which contributes to perceptual load (Alvarez \& Cavanagh, 2004; Battle et al., 2020; Beringer et al., 1988) by using double-barreled bicolored icons (see Figure 1). In Experiment 3, we mixed the two kinds of displays to reduce stimulus homogeneity and predictability. We reckoned that Experiment 3 should be the most challenging because the changing number of dimensions in the displays makes a target less predictable and requires increased attentional resource allocation. The three experiments were given in a fixed order in a within-subject experimental design so as to gradually increase task difficulty.
For the measurement of personality, participants completed the Big Five Inventory (BFI; Costa \& McCrae, 1992) and the Autism Spectrum Quotient scales (AQ; BaronCohen et al., 2001). The five factors are Extroversion (E), Openness (O), Agreeableness (A), Conscientiousness (C), and Neuroticism $(\mathrm{N})$. Extroversion measures enthusiasm, excitement-seeking, positive emotions, and warmth. A meta-analysis of studies on the relation of professional interests and the BFI showed that extroversion combined with an interest in enterprising showed the highest correlation (.50) with self-directed search (Larson et al., 2002). Openness measures curiosity, ideas, and imagination. In combination with an interest in art and aesthetics, openness was also correlated with self-directed search (.49; Larson et al., 2002). For this reason, we expected that extroversion and openness would be factors that help to more readily engage with a target in visual search.

Agreeableness and conscientiousness are more recent additions to the personality inventory of Costa and Mcrae (2008) to overcome limitations of earlier personality tests, which consisted of only the two personality factors neuroticism and extroversion (Eysenck \& Eysenck, 1975). Costa and Mcrae (2008) also wanted to measure factors such as trust, altruism, self-control, and the need for achievement. Agreeableness measures not only trust and altruism but also compliance and modesty, while conscientiousness measures dutifulness, selfdiscipline, and deliberation as well as an absence of impulsiveness. Analysis of visual search on webpage displays in three conditions, factual, interpretive, and exploratory, showed that highly conscientious participants performed better than those high in agreeableness and extroversion because they needed fewer and shorter fixations to extract relevant information (Al-Samarraie et al., 2017). Also, a study with professional airport controllers found that only conscientiousness significantly correlated with visual search accuracy (Biggs et al., 2017). Thus, of the "new" personality factors, conscientiousness was more relevant than agreeableness for visual search.

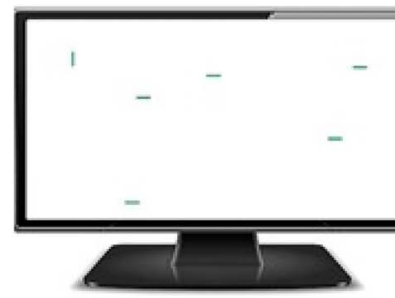

Experiment 1

Simple Stimuli

Target: Upper left corner

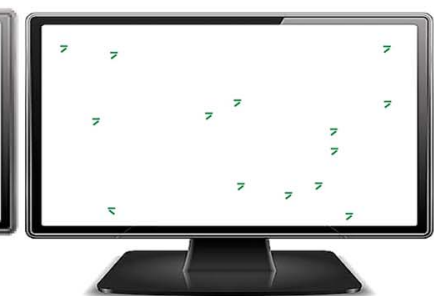

Experiment 2 Visually Complex Stimuli Target: Lower left corner

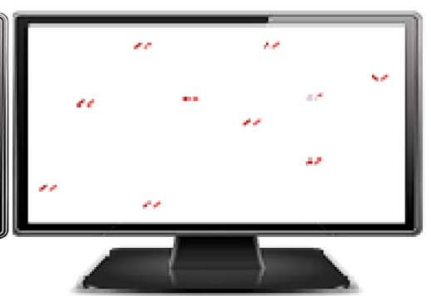

Experiment 3 Unpredictable Complexity Target: Upper right corner
Figure 1. Examples of the stimuli used in Experiments 1-3. Both target and distracter stimuli were randomly distributed and their location randomly changed from trial to trial. Set size varied between 6 , 10 , and 14 items. 
Neuroticism is possibly the most and at the same time least well-known personality factor (Weiss \& Deary, 2019). In the BFI, neuroticism measures negative feelings, irritation, low mood, and perceived stress. However, anxiety about others' perceptions of the own competence may have beneficial effects at work as especially highly neurotic men earned higher salaries, while in women, conscientiousness had a stronger effect on their earnings (Jonason et al., 2018). Participants high in neuroticism were more likely to draw out their RTs to achieve high accuracy (Flehmig et al., 2010). These extended RTs were exacerbated by changes in visual selection criteria (Nêcka \& Szymura, 2001). However, a slow response to change was also seen as a positive trait as people high in neuroticism would be more likely to persevere in the face of difficulty (Eysenck, 1970). We thus predicted that people with dominant neurotic traits would be more adept in the increasingly difficult visual search conditions.

Autistic personality traits as measured by the Autism Quotient (AQ) questionnaire (Baron-Cohen et al., 2001) are often perceived as counterproductive in social interactions and communication; however, social detachment may actually aid the search for a target. Adults with autism found especially serial search for a target less challenging than neurotypical adults (O'Riordan, 2004). Moreover, autism as a subclinical personality trait appeared to counteract perceptual load in visual search because of an enhanced ability to discriminate the target stimulus from distractors (Remington et al., 2012). We thus hypothesized that participants with a high AQ may perform well in the visual search tasks as they have a natural ability to process meaningless raw data and a preference for raw uncategorized perceptual information (e.g., O'Riordan, 2004).

Because we used a within-subjects design, we ensured that the same personalities impacted in each of the three experiments, but probably different aspects of their personalities would become relevant depending on the perceptual load. We expected that personality differences should show best under high or unpredictable perceptual load (Lavie, 1995) and when targets are absent because of the incremental search (Chun \& Wolfe, 1996). Rare targets (low prevalence effect) and target absent trials may provide a particularly strong test of personality traits because of the higher quitting threshold (Peltier \& Becker, 2017). Very often such trials produce exceptionally slow RTs which yield an ex-Gaussian distribution with a long RT "tail” (long RT tail; Shahar et al., 2014), meaning that a sizeable proportion of the sample shows extended latencies. Shahar et al. (2014) tested whether the long RT tail is produced because a high working memory load due to
(1) perceptual decisions, (2) fluctuations in attention or motivation, or (3) decision-making following rules of the task. Shahar et al. (2014) increased task difficulty by testing set size in arbitrary or nonarbitrary stimulus-response experiments and predicted that a high load generated by a large set size in interaction with arbitrary mappings of letters, digits, or shapes would produce extremely slow RTs. They indeed found that this most difficult condition produced an exGaussian distribution with a long RT tail of up to 3,000 ms. They also concluded that only non-decision time was responsible for extremely long RTs. A similar study with a low prevalence effect that produced a long RT tail in addition to tested brain potentials (Thorpe et al., 1996). Thorpe et al. (1996) found frontal lobe activity $150 \mathrm{~ms}$ after stimulus onset in target absent trials, but this was unrelated to the slow or fast RTs. They also concluded that RTs are not prolongated because of perceptual decision-making but because of an unspecified non-decision time factor. Indeed, recent research showed that social decision-making that involved sharing resources can produce very slow RTs of around 3,000 ms when adults weigh utility (Krajbich et al., 2015; see also Lynn \& Barrett, 2014). However, Shahar et al. (2014) and Thorpe et al. (1996) were less concerned about slow RTs in general, but about the long RT tail, that is extremely slow RTs that prevent a normal distribution of latencies. Because the simulations by Shahar et al. (2014) show that the long RT tails are caused by the duration of nonspecific decision time, and not by perceptual factors, attention or motivation, they suggest that further empirical research on individual differences may explain extremely extended RTs in visual search tasks. We report such a study where individual differences of personality are tested in their impact on visual search of targets (Experiment 1 ), increasing in visual complexity (Experiment 2), and decreasing in predictability (Experiment 3 ).

To summarize, based on the review, the hypotheses of the current set of experiments are that (1) extroversion and openness would facilitate target identification and (2) a high AQ would produce fast RTs even in conjunction search where targets and distracters share similar features. We further hypothesized that (3) highly conscientious participants would be able to maintain their speed in the face of increasing task difficulty, while (4) participants with dominant neurotic traits would show increased accuracy but extended RTs. Finally, the impact of these personality traits on visual search was expected to occur especially in Experiment 2 with visually more complex stimuli and in Experiment 3 where visual complexity was not predictable. 


\section{Experiment 1: Visual Search With Simple Stimuli}

\section{Methods}

\section{Participants}

$\mathrm{G}^{*}$ Power analysis for a multivariate ANOVA (MANOVA) with a within-subject factor with 12 measurements per experiment, an ES of .25, an $\alpha$ level of .05, and a power of .95 generated a minimum sample size of $N=45$. We tested all participants who consented without excluding any individual, that is, 71 participants aged $18-48$ years $(M=24$ years, $S D=6$ years) from the student population of an urban London university. There were $n=30$ men $(M=24$ years, $S D=4$ years) and $n=41$ women $(M=25$ years, $S D=6$ years). Participants had normal or corrected-tonormal vision. We screened for dyslexia with a selfassessment questionnaire and for color blindness with the Ishihara Colour Blindness Test (Ishihara \& Force, 1943). Data from one participant were discarded after the color blindness screening. Data of another participant were discarded because of technical failure causing missing data. Data from four participants were excluded because of outlier RTs (lower than 400 ms or greater than $3,500 \mathrm{~ms}$ ). This resulted in a final sample of $N=65$, with 27 male participants and 38 female participants.

\section{Apparatus and Stimuli}

The experiment was programmed in Visual Basic. The code is available at https://osf.io/ug32h/. Experiments were simultaneously presented with Visual Basic.NET on 20 computers (Pentium IV, $3.5 \mathrm{GHz}, 1,440 \times 900$ resolution LCD display, $75 \mathrm{MHz}$ refresh rate) in a laboratory in the Science Centre of the university. Computers were set up in individual cubicles to minimize distraction. Tasks were generic insofar as each task was randomly and individually produced for every participant according to an $a$ priori designed script. Self-paced responses were registered with a UK keyboard by pressing the "/" (forward slash) for a target or the " $z$ " key if no target was present. Feedback ("Correct" or "Incorrect") was displayed for $250 \mathrm{~ms}$ after each response. A fixation cross was presented for $600 \mathrm{~ms}$ at the beginning of each trial. The experiment had two blocks (pop-out, conjunction) with 144 trials each, that is, in total 288 trials. Participants were given 10 additional practice trials. In each block, targets were present in half of the trials, with the other half comprising no targets. All stimuli were randomly distributed on each trial across the 1,440 $\times 900$-pixel screen. Set size had three levels: 6, 10, or 14 stimuli. Stimuli were green singletons (Commission Internationale de L'Eclairage $=0.315$ ). The size was height $=0.25$ inches, and if they were tilted, the angle was $26.5^{\circ}$. In the pop-out condition (Block 1), targets differed from distractors only in orientation. In the conjunction condition (Block 2), some features were shared between targets and distracters, so they varied in orientation and size (small 0.15 inches among large 0.38 inches).

\section{Big Five Personality Inventory}

The inventory consists of a 44-item questionnaire (John et al., 1991; Version 4a). Statements are rated by participants on a 5-point scale, ranging from strongly agree to strongly disagree. The factors Extroversion (E), Openness $(\mathrm{O})$, Agreeableness (A), Conscientiousness (C), and Neuroticism $(\mathrm{N})$ were found to be invariant across culture, age, and sex (Costa \& Mccrae, 1992; but see Gurven et al., 2013). A meta-analysis of various versions of the Big Five Personality questionnaires by Hamby et al. (2016) analyzed 352 samples included in 288 studies and yielded 1,317 $\alpha$ coefficients based on a total sample size of 161,091 participants. $\alpha$ coefficients varied between .81 to .85 , and reliability varied between .76 and .85 .

\section{Autism Quotient}

A pen-and-paper copy of the Adult Autism Spectrum Quotient (AQ) questionnaire (Baron-Cohen et al., 2001) was used: https://psychology-tools.com/test/autismspectrum-quotient. The questionnaire evaluates five different areas: social skill, attention switching, attention to detail, communication, and imagination, with 10 items contributing to each category. Internal consistency scores of this questionnaire range from 0.63 to 0.77 (BaronCohen, et al., 2001). The questionnaire shows good test-retest reliability indicating that the test items are stable over time (Broadbent et al., 2013) as well as a high validity of the questionnaire as a self-report measure to quantify autistic traits (Woodbury-Smith et al., 2005). The maximum possible score was 50 points. Baron-Cohen et al. (2001) suggest that a score above 32 indicates Asperger syndrome. Ruzich et al. (2015) found in a sample of $N=1,374$ that an adult population has an average AQ of 17 , while the clinical population has a score of 35 . Males tended to score higher than females (18:15).

The AQ score measures whether a person has a reluctance to socialize. An agreement to statements such as "I find it hard to make new friends" adds to AQ score, while a statement such as "I enjoy social chitchat" does not add to AQ score. A high AQ score suggests that the person is not adept in communication and shows repetitive behaviors by agreeing to statements such as "I prefer to do things the same way over and over again." Also, other autistic traits such as high concentration "I frequently get so absorbed in one thing that I lose sight of other things", sensory sensitivity "I often notice small sounds when 
others do not", and attention to detail "I tend to notice details that others do not" are items where agreement would contribute to the AQ score.

\section{Procedure}

The study was approved by the departmental ethics committee. It was explained to participants that they could withdraw at any time. A debriefing session was offered upon completion of the experiments. Participants were not remunerated. They sat approximately $50 \mathrm{~cm}$ from the computer screen in an upright position and were asked to look for a right-tilted bar as this was always the same outlier in the target-present trials. Online instructions were:

"Please press the / key if you see a right-tilted bar. Alternatively, please press the $\mathrm{Z}$ key. Respond as accurately and quickly as possible. This experiment will have two blocks of trials. Press any key to start the practice trials."

\section{Data Generation}

Data were recorded for RT and accuracy. We computed error rates because especially nonserial searchers who would be less conscientious and thorough make more errors in visual search (Hogeboom \& Van Leeuwen, 1997). D prime $\left(D^{\prime}\right)$ was computed by subtracting the percentage of false alarms from the percentage of hits. This approach controls for chance responses if participants randomly or continuously pressed a key. RTs were averaged only for correct responses. Data are deposited on the Open Science Framework https://osf.io/ktud6/.

\section{Results}

We first analyzed sex differences in personality. T-tests for independent samples showed no significant differences between personality traits in men and women, $p s>.346$. A different picture emerged when the pattern of shared variance between traits was compared in split-sample correlations (see Table 1). The only significant correlation in men was a positive correlation of .50 between neuroticism and AQ. Neuroticism and AQ were also positively correlated in women although somewhat lower at .38. In women, openness was negatively correlated with both neuroticism at -.41 and extroversion at -.40 .

Scatterplots showed that women high on neuroticism were less open and extroverted, with more pronounced autistic traits indicating shyness. In contrast, extroversion was positively correlated with conscientiousness as
Table 1. Pearson correlations (two-tailed) between $B F I$ and $A Q$

\begin{tabular}{|c|c|c|c|c|c|c|}
\hline & 1. & 2. & 3. & 4. & 5. & 6. \\
\hline \multicolumn{7}{|c|}{ Total sample $(N=65)$} \\
\hline 1. Extroversion & 1 & .20 & -.18 & .19 & $.29 *$ & -.16 \\
\hline 2. Agreeableness & & 1 & -.10 & .16 & .12 & -.23 \\
\hline 3. Neuroticism & & & 1 & -.17 & .00 & $.41 * *$ \\
\hline 4. Openness & & & & 1 & .07 & $-.24^{\star}$ \\
\hline 5. Conscientiousness & & & & & 1 & -.04 \\
\hline 6. $A Q$ & & & & & & 1 \\
\hline \multicolumn{7}{|c|}{ Men ( $n=27 ;$ above the diagonal) } \\
\hline 1. Extroversion & 1 & .14 & -.23 & -.08 & .27 & -.01 \\
\hline 2. Agreeableness & .23 & 1 & -.29 & .34 & .31 & -.29 \\
\hline 3. Neuroticism & -.17 & .06 & 1 & -.05 & .09 & $.50 * \star$ \\
\hline 4. Openness & $-.40 *$ & .06 & $-.41^{\star}$ & 1 & -.08 & -.24 \\
\hline 5. Conscientiousness & $.32 *$ & -.02 & -.10 & .21 & 1 & .09 \\
\hline 6. $A Q$ & -.24 & -.20 & $.38 *$ & -.25 & -.14 & 1 \\
\hline & \multicolumn{6}{|c|}{ Women ( $n=38$; below the diagonal) } \\
\hline
\end{tabular}

Note. ${ }^{* \star} p<.01$ (two-tailed), ${ }^{\star} p<.05$ (two-tailed). AQ = Autism Quotient, $\mathrm{BFI}=$ Big Five Inventory.

women high in conscientiousness also tended to be more extroverted.

Because of the different profiles of personality traits in men and women, a split-sample by sex procedure was used when analyzing visual search involving personality traits as covariates.

$M$ and $S D$ per condition per experiment are listed in the Electronic Supplementary Material (ESM 1). RTs and accuracy data were analyzed in a 2 (target: present or absent) $\times 2$ (pop-out/conjunction) $\times 3$ (Set Size: 6,10 , or 14) MANOVA with repeated measures on all factors. The degrees of freedom were adjusted according to Huynh-Feldt when the Mauchly's test of sphericity was significant. We report accuracy before RTs. After the report of the results for the visual search task, the full scores of the personality variables inclusively the AQ score were added to the model as covariates. When a covariate was significant, this personality variable was dichotomized at the median and the model rerun with just this one between-subject variable as a post hoc test to obtain group means that could be compared and plotted.

\section{Accuracy}

There was a main effect of target presence, $F(1$, $65)=55.04, p<.001, \eta^{2}=.46$. As could be expected, accuracy was higher when the target was present $(M=91.3 \%)$ than when absent $(M=86.2 \%)$. No other effect was significant, $p s>.146$.

\section{Reaction Times}

RT analyses yielded highly significant statistical effects for all factors and two-way interactions, $p s<.001$. Participants 
showed longer response times when a target item was absent $(M=1,239 \mathrm{~ms})$ than when a target was present $(M=978 \mathrm{~ms}), F(1,65)=106.71, p<.001, \eta^{2}=.62$ as search is more exhaustive and needs to be aborted when no target can be found. The two-way interaction of target presence with pop-out search was significant, $F(1,65)=17.92$, $p<.001, \eta^{2}=.22$, insofar as the target was detected faster in pop-out search when it was present $(M=1,059 \mathrm{~ms})$ than when it was absent $(M=1,416 \mathrm{~ms})$. If distracters shared features with the target in conjunction search, it also took longer when the target was absent $(M=1,061 \mathrm{~ms})$ than when it was present $(M=898 \mathrm{~ms})$, but the difference was not as large.

The main effect of set size was significant as expected, $F(1.68,65)=40.93, p<.001, \eta^{2}=39$, with the number of distracters slowing down RTs (6 items: $M=1,035 \mathrm{~ms}, 10$ items: $M=1,099 \mathrm{~ms}, 14$ items: $M=1,191 \mathrm{~ms})$. The linear polynomial contrast was significant, $F(1,65)=56.27$, $p<.001, \eta^{2}=.47$, while the quadratic trend was not, $p=.207$. The presence of the target was important for the effect of set size, $F(1.62,65)=8.62, p<.001, \eta^{2}=.12$. When the target was absent, the decision time was longer and more distracters were present ( 6 items: $M=1,128 \mathrm{~ms}, 10$ items: $M=1,127 \mathrm{~ms}, 14$ items: $M=1,361 \mathrm{~ms})$. Latencies were faster when a target was present and increased not as much (6 items: $M=943 \mathrm{~ms}, 10$ items: $M=971 \mathrm{~ms}, 14$ items: $M=1,021 \mathrm{~ms})$.

Pop-out $(M=1,238 \mathrm{~ms})$ was slower than conjunction $(M=980 \mathrm{~ms})$ search, $F(1,65)=21.84, p<.001, \eta^{2}=25$. Pop-out versus conjunction search in interaction with set size was significant, $F(1.62,65)=11.88, p<.001, \eta^{2}=.16$. In pop-out search, RTs increased considerably with set size (6 items: $M=1,114 \mathrm{~ms}, 10$ items: $M=1,231 \mathrm{~ms}, 14$ items: $M=1,368 \mathrm{~ms}$ ), while for conjunction search, RTs hovered around 1,000 ms (6 items: $M=957 \mathrm{~ms}, 10$ items: $M=968 \mathrm{~ms}, 14$ items: $M=1,014 \mathrm{~ms})$. Thus, in this experiment with monochrome green singletons, it was easier to find a target among distracters that varied in two dimensions, namely orientation and size, than just in orientation.

When controlling for sex differences, the only significant effect was an interaction of sex with the target absent/ present effect, $F(1,65)=5.27, p=.025, \eta^{2}=.08$. Women showed longer response times when the target was absent ( $M=1,308 \mathrm{~ms})$ than men $(M=1,141 \mathrm{~ms})$, but when the target was present, they decided at about the same speed target (women $M=1,001 \mathrm{~ms}$; men $M=947 \mathrm{~ms}$ ). This showed that women searched more diligently for a target until deciding that there was no target present.

\section{Personality Variables}

We then added the personality covariates of the BFI and $\mathrm{AQ}$ and ran the model with a sex-split sample (compare groups).

\section{Accuracy}

There was a significant effect of openness in the female sample, $F(2,38)=4.67, p=.038, \eta^{2}=.13$. The scatterplot showed in women; the higher they scored on openness, the higher was their accuracy, $r=-.34, p=.037$ (two-tailed). Men both high and low in openness scored high in accuracy, $r=.27, p=.174$ (two-tailed).

\section{Reaction Times}

Two significant main personality effects of about equal strength were found in the male sample, of extroversion, $F(2,27)=5.24, p=.033, \eta^{2}=.21$, and of AQ $F(3,27)=5.48$, $p=.030, \eta^{2}=.21$, while there were no main effects of personality in women, $p s>.494$. Scatterplots showed that the higher the extroversion score in men, the slower the RTs, but the correlation between extroversion and RTs was not significant, $r=.30, p=.133$ (two-tailed). In contrast, the higher the AQ score, the faster the RTs and these two variables were significantly correlated, $r=-.48$, $p=.012$.

Neuroticism had a significant influence on the target absent/present by set size effect, $F(3,27)=3.35, p=.045$, $\eta^{2}=.14$ in men. To follow up the significant three-way interaction, we ran the sex-split (compare groups) MANOVA with neuroticism as a between-subject variable.

A two-way interaction of set size and neuroticism showed that highly neurotic men were looking for a shorter time and broke off their search quicker than men scoring lower on neuroticism, $F(2,27)=3.38, p=.042, \eta^{2}=.12$ (see Figure 2; left graph, solid black line). The target absent/ present two-way interaction and the full three-way

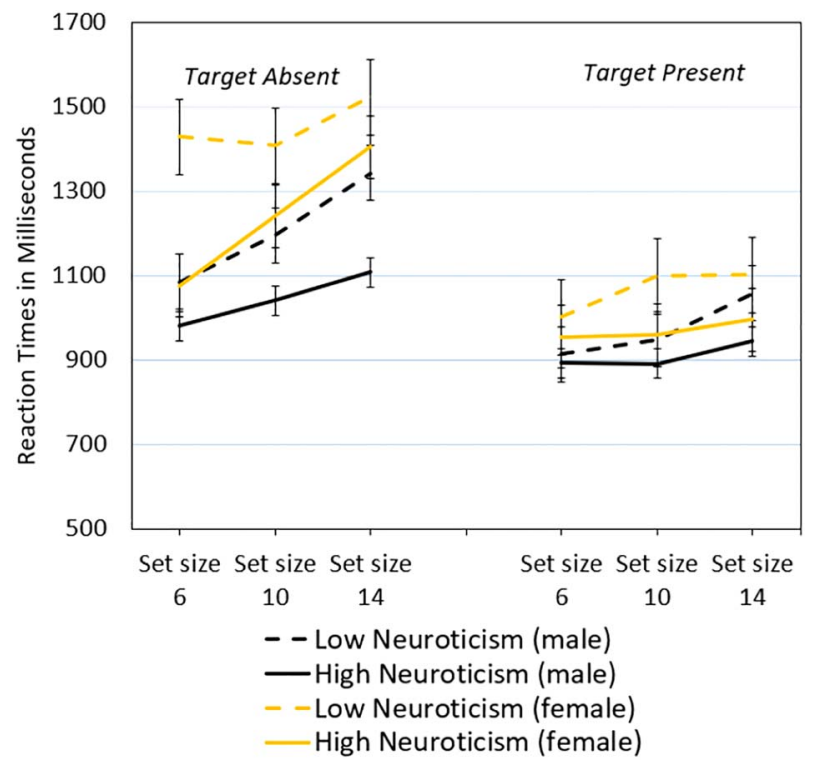

Figure 2. Experiment 1. Visual search time depending on neuroticism. Error bars denote the SE. 


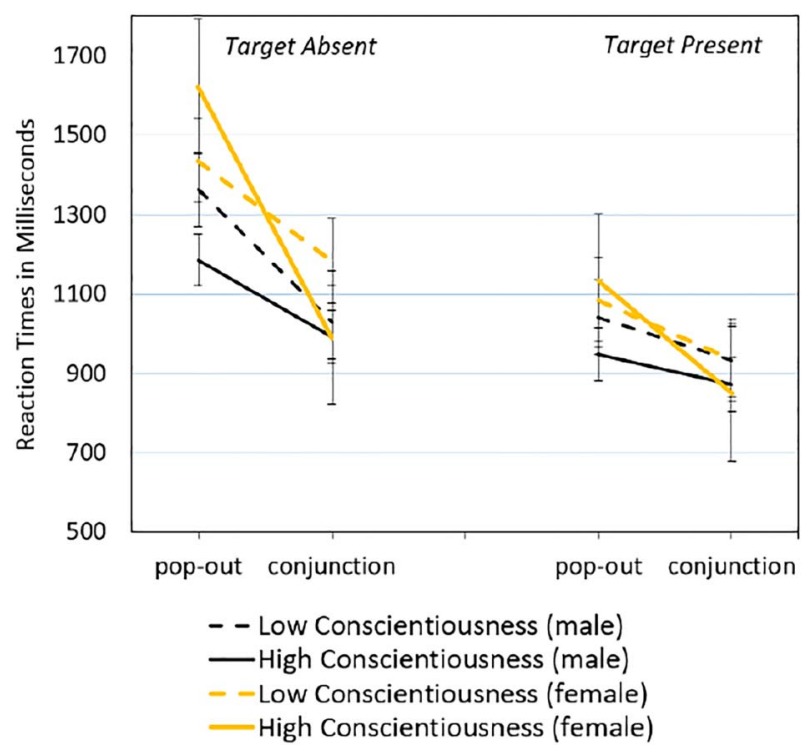

Figure 3. Experiment 1. Visual search time depending on Women's conscientiousness. Error bars denote the SE.

interaction with neuroticism did not reach significance, ps $>.094$.

In this post hoc test, the three-way interaction of target absent/present by set size effect by neuroticism was significant in women, $F(2,38)=3.39, p=.039, \eta^{2}=.09$. Women low in neuroticism searched for longer for an absent target also under low cognitive load (see Figure 2; left graph, dashed orange line). These results showed that in both men and women, high neuroticism shortened RTs as expected.

In the women sample, a significant effect of conscientiousness on pop-out versus conjunction search was revealed, $F(1,38)=4.15, p=.050, \eta^{2}=.12$. The follow-up of the significant interaction with a sex-split (compare groups) MANOVA with conscientiousness as a dichotomous between-subject variable as expected showed no significant effects of conscientiousness in men, $p s>.162$, while in women, the three-way interaction of pop-out versus conjunction by target absent/present by conscientiousness was approaching significance, $F(1,38)=3.77, p=.060, \eta^{2}=.09$.

Figure 3 (left graph, solid orange line) shows that when the target was absent, highly conscientious women showed extended RTs to find an absent target in the pop-out search and a shorter time in the conjunction condition than less conscientious women. Given that in pop-out search, a target would have been more readily perceptible than in conjunction search, an earlier abortion of the search would have been the more efficient and appropriate strategy.

To summarize, men with higher autistic traits were quicker to decide about target presence. Highly neurotic men and women were faster and broke off the search in a comparably shorter time. In contrast, women low in neuroticism and those highly conscientious took more time and searched for longer when the target was absent.

\section{Experiment 2: Visual Search With Complex Stimuli}

In the second experiment, we tested the same participants with more complex stimuli. The hypothesis was that visual complexity would deepen the sex differences and strengthen the statistical effects of the personality variables. We introduced a second color as this makes the distracters in visual search more powerful than monocolored stimuli (Weichselbaum \& Ansorge, 2018).

\section{Methods}

Participants were the same as in Experiment 1.

\section{Apparatus and Procedure}

The number of blocks and trials were the same as in Experiment 1. The complex stimulus set was composed of double-barreled items (e.g., two aligned strokes). The two elements were red or green, for example. In the pop-out condition, the targets differed from the distracters only in one dimension, either size (small $=0.15$ inches, large $=$ 0.38 inches) or orientation. Another possibility was that the elements had different colors. These were either two different colors, or colors differed in luminance. In the conjunction condition, the double-barreled items had one part of the two-element item that was shared with the target, while the second part would be different in color or position. Participants were told to "Please press the / key if you see an element that differs from the others. Alternatively, press the $\mathrm{z}$ key. Respond as accurately and quickly as possible."

\section{Results Experiment 2}

\section{Accuracy}

As in Experiment 1, there was a main effect of whether the target was present or absent, $F(1,65)=50.68, p<.001$, $\eta^{2}=.44$, with a medium ES. Accuracy was higher when the target was present $(M=90.8 \%)$ than when absent $(M=84.8 \%)$.

Pop-out search was more accurate $(M=92.0 \%)$ than conjunction search $(M=83.6 \%), F(1,65)=77.50, p<.001$, $\eta^{2}=.55$. This effect varied based on whether the target was present or absent, $F(1,65)=17.41, p<.001, \eta^{2}=.21$. When 
the target was present, pop-out search accuracy was slightly higher $(M=93.0 \%)$ than when it was absent $(M=91.0 \%)$, but in the conjunction search, this difference was much more pronounced (target present $M=88.5 \%$, target absent $M=78.6 \%$ ).

There was also a main effect of set size in search accuracy, $F(2,65)=4.03, p=.020, \eta^{2}=.06$, as fewer distracters lead to better accuracy (6 items: $M=89.1 \%, 10$ items: $M=87.1 \%, 14$ items: $M=87.2 \%)$. The linear polynomial contrast was significant, $F(1,65)=5.15, p=.027$, $\eta^{2}=.07$, while the quadratic trend was not, $p=.118$.

The control of the model for sex differences did not yield a significant main effect of sex, $p=.510$, nor interaction effects with sex, $p s>.259$.

\section{Reaction Times}

RT analyses yielded highly significant statistical effects for all factors and two-way interactions, $p s<.001$. Participants showed shorter response times when a target item was present $(M=1,154 \mathrm{~ms})$ than when absent $(M=1,426 \mathrm{~ms})$, $F(1,65)=73.06, p<.001, \eta^{2}=.53$, because of ease of decision-making when a target can be found.

This experiment with complex stimuli showed that popout $(M=1,033 \mathrm{~ms})$ was faster than conjunction search $(M=1,547 \mathrm{~ms}), F(1,65)=116.45, p<.001, \eta^{2}=.64$. The main effect of set size again showed, $F(1.88,65)=36.71$, $p<.001, \eta^{2}=.37$, that a larger amount of distracters slowed down RTs (6 items: $M=1,186 \mathrm{~ms}, 10$ items: $M=1,302 \mathrm{~ms}$, 14 items: $M=1,382 \mathrm{~ms})$. The linear polynomial contrast was significant, $F(1,65)=56.49, p<.001, \eta^{2}=.47$, while the quadratic trend was not, $p=.275$. The presence of the target was important for the effect of set size, $F(2$, $65)=12.19, p<.001, \eta^{2}=.16$. When the target was absent, RTs were longer, and more distracters were present (6 items: $M=1,280 \mathrm{~ms}, 10$ items: $M=1,430 \mathrm{~ms}, 14$ items: $M=1,568 \mathrm{~ms}$ ), but latencies were quicker when a target was present and increased not as much (6 items: $M=1,090 \mathrm{~ms}, 10$ items: $M=1,175 \mathrm{~ms}, 14$ items: $M=1,197 \mathrm{~ms})$.

The two-way interaction of target presence with popout/conjunction search was significant, $F(1,65)=80.10$, $p<.001, \eta^{2}=.56$. The target was detected somewhat faster in pop-out search when it was present $(M=1,019 \mathrm{~ms})$ than when it was absent $(M=1,047 \mathrm{~ms})$. This was the same in conjunction search as it also took longer when the target was absent $(M=1805 \mathrm{~ms})$ than when it was present $(\mathrm{M}=1,289 \mathrm{~ms})$, but the difference was much larger.

The classic effect of pop-out versus conjunction search in interaction with set size was significant, $F(1.84$, $65)=15.33, p<.001, \eta^{2}=.19$. In pop-out search, RTs increased somewhat with the number of distracters $(6$ items: $M=983 \mathrm{~ms}, 10$ items: $M=1,041 \mathrm{~ms}, 14$ items: $M=1,076 \mathrm{~ms}$ ), but this increase was more pronounced for conjunction search (6 items: $M=1,389 \mathrm{~ms}, 10$ items: $M=1,564 \mathrm{~ms}, 14$ items: $M=1,688 \mathrm{~ms})$. Thus, with complex stimuli, the expected increase in search difficulty in conjunction search was found.

When controlling the results for sex differences, the main effect and interactions were all nonsignificant, $p s>.202$.

\section{Personality Variables}

We then added the personality covariates of the BFI and AQ and ran the model with a sex-split sample (compare groups).

\section{Accuracy}

There were neither significant effects of personality traits in the male, $p s>.089$, nor in the female sample, ps $>.111$.

\section{Reaction Times}

There was no significant effect of personality on visual search in the male sample, $p s>.106$. However, in the female sample, the set size effect in pop-out versus conjunction search was dependent on the level of their openness, $F(2,38)=3.79, p=.028, \eta^{2}=.11$, with women less open to experience showing longer and more steeply increasing latencies with set size than in those women who were more open. However, the follow-up of the significant interaction with a sex-split (compare groups) MANOVA with openness as a between-subject variable showed no significant effects of openness in the men sample, ps $>.467$, nor in the women sample, $p$ s $>.106$, and thus, the data are not plotted.

Moreover, in the female sample, a significant effect of extroversion occurred in a four-way interaction of the popout/conjunction search with the number of distracters and the presence or absence of the target, $F(2,38)=3.68$, $p=.031, \eta^{2}=.11$. The follow-up of the significant interaction with a sex-split (compare groups) MANOVA with extroversion as a between-subject variable did not reach significance in the men sample, $p s>.098$, but the four-way interaction was significant in the women sample, $F(2$, $38)=4.09, p=.021, \eta^{2}=.10$. Women with more introverted personalities searched for a long time in conjunction displays when the target was absent with RTs over 2,250 ms (orange dashed lines in panel A of Figure 4), while their RTs were much quicker when the target was present (see panel B of Figure 4).

To summarize, highly extroverted participants were more efficient in their RTs when no target was present. This was most likely to be significant only in women because the correlations between personality traits showed that in women, openness and extroversion were variables with significant amounts of shared variance while this was not the case in men. 


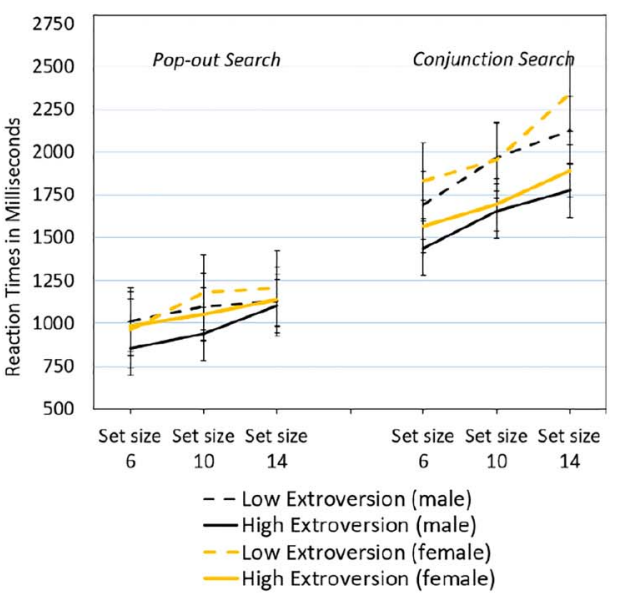

(A) Target absent

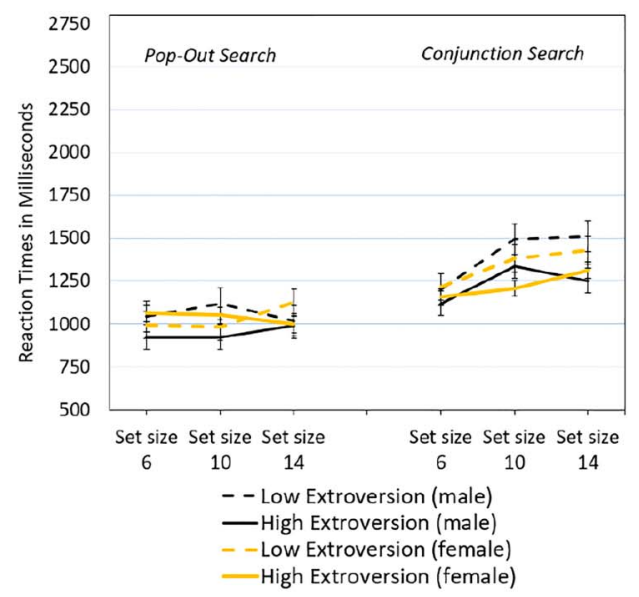

(B) Target present
Figure 4. Experiment 2. Impact of extroversion on pop-out and conjunction search. Error bars denote the SE.

\section{Experiment 3: Unpredictable Stimulus Complexity}

The third experiment differed from the previous experiments insofar as search displays with simple and complex items appeared in an unpredictable sequence.

\section{Methods}

Participants were the same as in Experiments 1 and 2.

\section{Apparatus and Stimuli}

Stimuli were randomly drawn from a pool of those used in Experiments 1 and 2. There were 36 arrays with simple stimuli, 36 arrays with complex stimuli, again amounting to 72 with and 72 without target trials $=144$ trials, in two blocks amounting to 288 trials in total. Instructions were the same as in Experiment 2.

\section{Results Experiment 3}

\section{Accuracy}

There was a main effect of whether the target was present or absent, $F(1,65)=26.55, p<.001, \eta^{2}=.30$. Accuracy in general was low, but higher when the target was present $(M=49.5 \%)$ than when absent $(M=44.3 \%)$.

Pop-out search was less accurate $(M=45.0 \%)$ than conjunction search $(M=48.8 \%), F(1,65)=40.13, p<.001$, $\eta^{2}=.39$, but again this was dependent on whether the target was absent or present, $F(1,65)=8.49, p=.005$, $\eta^{2}=.12$. When the target was absent, pop-out search accuracy was slightly higher $(M=46.2 \%)$ than when it was present $(M=43.7 \%)$, but in conjunction search, the difference was more pronounced (target absent $M=52.7 \%$, target present $M=44.9 \%$ ).

When displays varied in visual complexity in unpredictable ways, the number of distracters as such did not matter, $F(2,65)=1.24, p=.293$, but set size did interact two-way with pop-out versus conjunction search, $F(1$, $65)=32.46, p<.001, \eta^{2}=.33$, two-way with target presence, $F(1,65)=29.00, p<.001, \eta^{2}=.31$, and three-way with both these factors, $F(1,65)=18.89, p<.001, \eta^{2}=.23$. When the target was present, in pop-out search, accuracy increased in displays along with the number of distracters (6 items: $M=42.9 \%, 10$ items: $M=45.7 \%, 14$ items: $M=50.2 \%$ ), while in conjunction search, accuracy was higher but reduced in displays with the most distracters (6 items: $M=59.0 \%, 10$ items: $M=58.3 \%, 14$ items: $M=40.8 \%$ ). This was not the case when the target was absent as pop-out search (6 items: $M=41.5 \%, 10$ items: $M=39.1 \%, 14$ items: $M=50.5 \%)$ and conjunction search were at the same low level ( 6 items: $M=42.0 \%, 10$ items: $M=43.4 \%, 14$ items: $M=49.2 \%)$.

The control of the model with the sex variable revealed an interaction of sex with pop-out versus conjunction search and target presence, $F(1,65)=8.81, p=.004$, $\eta^{2}=.12$. Male participants showed no difference in popout search whether the target was absent $(M=43.89 \%)$ or present $(M=43.98 \%)$, but accuracy was higher in conjunction search when the target was absent $(M=53.5 \%)$ rather than present $(M=42.1 \%)$. Female participants showed higher accuracy in the target absent trials (pop-out $M=47.9 \%$; conjunction $M=52.1 \%$ ) than target present trials (pop-out $M=43.6 \%$; conjunction $M=46.7 \%)$. 


\section{Reaction Times}

Participants showed shorter response times when a target was present $(M=1,009 \mathrm{~ms})$ than when it was absent $(M=1,337 \mathrm{~ms}), F(1,65)=65.08, p<.001, \eta^{2}=.50$, because of ease of decision-making when a target can be found.

Also, this experiment with stimuli of different levels of complexity showed that pop-out $(M=1,020 \mathrm{~ms})$ was faster than conjunction search $(M=1,326 \mathrm{~ms}), F(1,65)=116.42$, $p<.001, \eta^{2}=.63$. This effect occurred independently of whether the target was absent or present, $F(1,65)=3.11$, $p=.082$.

The main effect of set size was significant, $F(1.83,65)=$ $26.90, p<.001, \eta^{2}=.30$, showing that a greater number of distracters slowed down RTs ( 6 items: $M=1,079 \mathrm{~ms}, 10$ items: $M=1,210 \mathrm{~ms}, 14$ items: $M=1,231 \mathrm{~ms})$. The linear polynomial contrast was significant, $F(1,65)=37.42$, $p<.001, \eta^{2}=.37$, and so was the quadratic trend, $F(1,65)=$ $10.28, p=.002, \eta^{2}=.14$, although with a smaller ES. The presence of the target was important for the effect of set size, $F(2,65)=9.25, p<.001, \eta^{2}=.13$. When the target was absent, search took longer, the more distracters were present ( 6 items: $M=1,199 \mathrm{~ms}, 10$ items: $M=1,370 \mathrm{~ms}, 14$ items: $M=1,442 \mathrm{~ms}$ ). Latencies were quicker when a target was present and hovered around $1,000 \mathrm{~ms}$ (6 items: $M=958 \mathrm{~ms}, 10$ items: $M=1,050 \mathrm{~ms}$, 14 items: $M=1,021 \mathrm{~ms})$.

The classic effect of pop-out versus conjunction search in interaction with set size was significant, $F(1,65)=10.61$, $p<.001, \eta^{2}=.14$. In pop-out search, RTs increased somewhat with the number of distracters (6 items: $M=975 \mathrm{~ms}, 10$ items: $M=1,056 \mathrm{~ms}, 14$ items: $M=1,030 \mathrm{~ms}$ ), but this increase was more pronounced for conjunction search (6 items: $M=1,183 \mathrm{~ms}, 10$ items: $M=1,364 \mathrm{~ms}, 14$ items: $M=1,432 \mathrm{~ms})$. Thus, also in this experiment with different levels of complexity in an unpredictable sequence, the expected increase in search difficulty could be found in the conjunction search.

Thus, the unpredictability of visual stimulus complexity hardly changed the experimental effects in RTs despite drastically lowered accuracy. When controlling for sex differences, the main effect and the interactions were all nonsignificant, $p \mathrm{~s}>.101$.

\section{Personality Variables}

We again added the personality covariates of the BFI and AQ and ran the model with a sex-split sample (compare groups).

\section{Accuracy}

There were no significant effects of personality traits or AQ in the male sample, $p s>.068$, nor in the female sample, ps $>.096$.

\section{Reaction Times}

There was a significant three-way interaction of agreeableness with pop-out versus conjunction search and target presence in men, $F(1.84,27)=5.85, p=.025, \eta^{2}=.23$, and in the women sample, $F(1,38)=4.61, p=.040, \eta^{2}=.13$. Highly agreeable women took more time to decide when the target was absent in the conjunction search than women scoring lower on agreeableness, while in men the reverse was true. The follow-up sex-split (compare groups) MANOVA with agreeableness as a between-subject variable showed no significant effects of agreeableness in the men sample, $p s>.190$, nor in the women sample, $p s>.150$; hence, the group means are not plotted.

Moreover, an effect of neuroticism in men was found when they had to decide on the presence of a target depending on the number of distracters, $F(2,27)=3.79$, $p=.031, \eta^{2}=.16$. The follow-up sex-split (compare groups) MANOVA with neuroticism as a dichotomous betweensubject variable showed a marginally significant three-way interaction of target presence, set size, and neuroticism in men, $F(2,27)=3.15, p=.052, \eta^{2}=.11$, and in women, $F(1$, $38)=3.83, p=.058, \eta^{2}=.10$. Figure 5 (left graph, orange and black solid lines) shows that both highly neurotic men and women were faster to decide that a target was absent than their same-sex peers scoring lower on neuroticism. Latencies increased under cognitive load of greater number of distracters. When the target was present, there were no individual differences.

To summarize, Experiment 3 showed that the inconsistency of displays, with varying visual stimulus complexity, led to a drastic performance decrement in accuracy in both men and women, yet with similar experimental effects for RTs as before. Neuroticism accelerated correct decision-making in both men and women. However, there was an opposite effect of agreeability in the two sexes. Men tending to agree were making faster decisions when the search became difficult, while women with high agreeability scores were cautious and generally took more time to make a decision.

\section{Comparison of Experiments 1-3}

To control any general task difficulty effects with regard to within-subject effects in accuracy and RTs, we created aggregate accuracy and RT variables across experimental conditions for each of the experiments. We ran a onefactorial ANOVA with repeated measures for accuracy and RTs on the factor experiment with three levels for the three experiments. We then controlled for sex differences, and personality variables as covariates as before. 


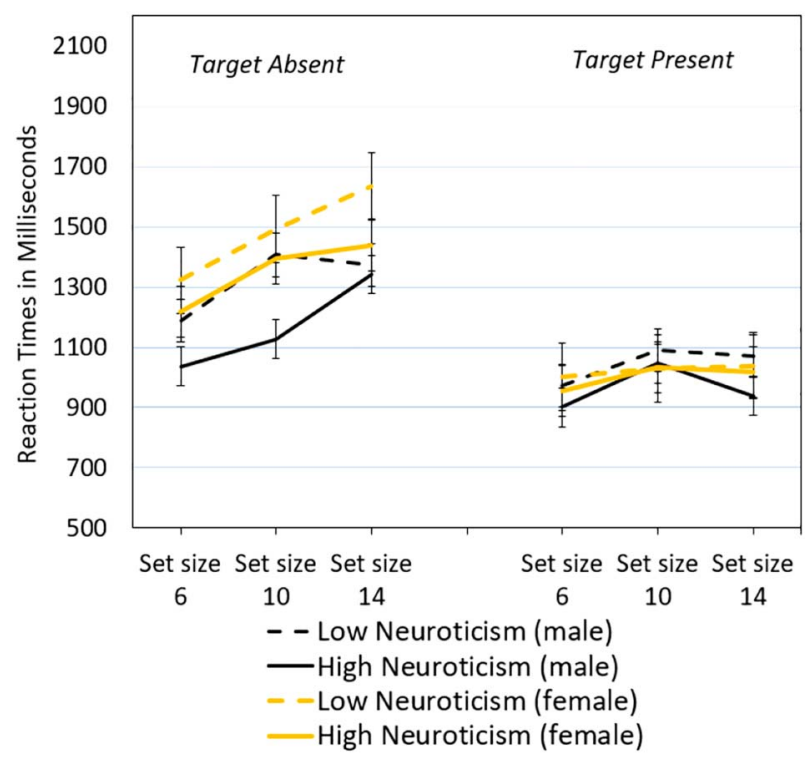

Figure 5. Experiment 3. Impact of neuroticism on distracter processing. Error bars denote the SE.

\section{Accuracy}

The main effect of the experiment was highly significant, $F(2,65)=773.94, p<.001, \eta^{2}=.92$. Pairwise comparisons within the model showed that there was no difference in accuracy level between Experiments $1(M=88.8 \%)$ and 2 ( $M=87.8 \%)$, but accuracy in Experiment $3(M=46.9 \%)$ was significantly lower. This was the case independently of sex, $p s>.117$, and personality variables, in males, $p s>.338$, and females, $p s>.235$.

\section{Reaction Times}

The main effect of the experiment was significant, $F(2$, $65)=9.67, p<.001, \eta^{2}=.13$. Pairwise comparisons within the model showed that RTs were significantly faster in Experiment 1 with just singletons $(M=1,109 \mathrm{~ms})$ and in Experiment 3 with both singletons and double-barreled stimuli $(M=1,173 \mathrm{~ms})$ than in Experiment $2(M=1,290 \mathrm{~ms})$ with just the visually complex stimuli. This was the case independently of sex, $p s>.338$, and personality variables, in males, $p$ s $>.075$, and females, $p$ s $>.071$.

\section{Discussion}

Our aim was to investigate the effect of personality on visual search. In a series of three experiments, we increased task difficulty levels by increasing stimulus complexity (singleton vs. double-barreled items) and predictability of visual complexity. This increase in task difficulty significantly lowered accuracy in the third experiment when stimulus complexity was unpredictable. Latencies in the three experiments appeared to be dependent on stimulus complexity as RTs for simple onedimensional monocolored stimuli were fast, for complex bicolored stimuli RTs were significantly slower, and the third experiment that included trials with both simple and complex stimuli showed RTs that were in between which reflected the affordances of the perceptual process and the absence of perceptual learning in the three experiments. Fatigue effects can only be observed with very large set sizes of 24 and 36 items (Wang \& Hou, 2020).

\section{The Visual Search Experiments}

The visual search experiments showed a number of expected effects, which did not vary across the three experiments. Latencies were longer when the target was absent because participants wanted to make sure that they did not miss out on the detection of the target. Pop-out search was faster than conjunction search as the target did not share features with the distracters. A larger number of distracters slowed down RTs more than fewer distracters, and we found a significant linear trend for this effect in all three experiments. The classic effect that RTs increased with the number of distracters in conjunction but not in pop-out search was borne out only in Experiments 2 and 3 with the visually complex stimuli, but not in Experiment 1 with singletons. Thus, the increase in visual complexity did produce the intended effect of a stronger challenge.

These main effects of target presence shared features between target and distracters and the number of distracters interacted, with absent targets and a higher number of distracters magnifying the main effects. In accordance with Shahar et al. (2014), extremely long RTs were found in these target absent and large set size conditions and personality effects showed particularly here. It was not the case that the added visual complexity in Experiment 2 produced the more impact of personality variables due to perceptual load; instead, different personality aspects were relevant when processing visually complex stimuli rather than singletons.

Experiment 1 did not yield as many experimental effects in accuracy as Experiment 2, but in both experiments, accuracy was higher when the target was present than when it was absent. In contrast, in Experiment 3, the heterogeneity of various stimulus arrays in terms of complexity led to a very pronounced drop in accuracy by about half. Stimulus consistency has been shown before as more important than stimulus complexity (Plude et al., 
1982). In Experiment 3, the easiest condition of a present target with few distracters increased accuracy to $60 \%$, but this still fell short of accuracy levels of more than $80 \%$ in Experiments 1 and 2. Importantly, Plude et al. (1982) controlled for visual complexity by either having oneletter or two-letter items. The level of visual complexity did not interact with presentation consistency. Thus, it is in line with this previous research that we found that consistency was having a larger effect on accuracy of visual search than visual complexity.

\section{Personality and Visual Search}

Accuracy of visual search is particularly relevant for professional scanning, for instance, at airports (Biggs \& Mitroff, 2014). There were no effects of personality traits on accuracy in the three experiments, with the exception of Experiment 1 with singleton stimuli as women who scored high on openness were more accurate in their identification of the target. Openness to experience is often found in creative personalities (Mccrae, 1987). A heightened esthetic sensitivity for composition is an important personality factor in open-minded people (Coan, 1972; Palmer et al., 2013) and in visual search displays with singletons this view on the composition of the whole array was helpful.

In Hypothesis 2, we had expected based on previous research (Remington et al., 2012) that participants' performance would be less prone to deteriorate under high perceptual load with larger numbers of distracters if they show a high score of autistic traits. However, in the current study, such an advantage turned out as a main effect of AQ only in Experiment 1 with singletons. The higher men's AQ score, the faster was the recognition and decision that a target is absent. Consistent decision-making in people with autistic traits is a reliable result in many studies across various topics (De Martino et al., 2008; Farmer et al., 2017; Lange-Küttner et al., 2019; South et al., 2014). In contrast, highly conscientious women searched for longer when the target was absent even in the pop-out condition where it would have been readily perceptible. Hence, when a search array was perceptually simple, fast speed seems to have been a focus of men with autistic traits, while conscientious women searched for longer, even in relatively simple pop-out searches.

Another personality factor that was responsible for fast and correct decision-making in visual search was neuroticism, for both sexes, in Experiment 1 with singletons and in Experiment 3 that contained displays with singletons. Men and women who scored high in neuroticism were looking for a shorter time and made faster decisions to abort the search when there was no target present but were still sensitive to the number of distracters. This showed great efficiency in the identification of simple visual targets. The result appears to disconfirm Hypothesis 4, which was based on Newton et al's. (1992) finding that high neuroticism correlated with slow RTs in target-absent trials. Newton et al. used letters which were similarly complex as the double-barreled stimuli in Experiment 2. Instead, we obtained neuroticism-accelerated RTs in search arrays with singletons and no effect of neuroticism with visually complex stimuli. In both men and women in the current study, neuroticism was significantly correlated with the AQ score and as explained above, sub-clinical autistic traits facilitate in various areas where consistent and efficient decision-making was required.

In another recent study, when comparing four types of displays for visual exploration, first, interest for colors in a grid, second, for gray-scale visual segments, third, for written words in different font types and sizes, and, fourth, for different types text alignment without letters being visible, eye tracking showed that the displays with letters were of particular interest for participants with high neuroticism (high anxiety and cautiousness; Al-Samarraie et al., 2018). Participants with a high score on the neuroticism factor appeared to search arrays with words written in differently sized fonts more widely, while eye movements related to other personality dimensions clustered just above the central fixation point.

Dhinakaran et al. (2014) correlated the BFI personality factors with a rapid serial visual presentation of letters, which produces an attentional blink that involves missing out on a second target after discovering the first. They used two overlapping streams, one slow with large letters and one fast with small letters. Participants were given the instruction to ignore one stream or the other. When neuroticism was high, the focus on the fast stream of small letters was more challenging than the slow stream with large letters. In contrast, extroversion was helpful for the fast stream of small letters.

Before agreeing with these authors' conclusion that the results showed neurotics' overinvestment of attention and a stronger spatial focus on salient, bigger stimulus features, it is worth noting results from a training study of strategies in visual search. Wang et al. (1997) trained participants to avoid visiting locations twice during search for a target in images of soldering boards, with several groups of large amounts of very small dots. Training was successful insofar as such systematic search increased the target detection rate as opposed to unsystematic random search, which degraded detection accuracy. The interesting part of this study is, however, that the pretraining measures Embedded Figures Test and a digit span test did not predict the success; instead, foveal acuity did. 
Maximum foveal acuity arises from a $1.5-\mathrm{mm}$ wide deepening in the retinal photoreceptor layer in the eye, composed entirely of cones. Foveal acuity correlated with accuracy at $.71 \mathrm{in}$ untrained visual search and with search stopping time at .69 in trained systematic search. This showed the importance of foveal acuity for visual search (see also Chan \& Courtney, 1996). Also, recent research suggests a target in a random location in a search array is best detected with a combination of high foveal acuity and a nonexhaustive search pattern (Juni \& Eckstein, 2017). Thus, strongly diminished size or increased visual complexity would be a challenge for foveal acuity in high neuroticism scorers who thrive in fast decision-making involving clear and simple stimulus arrangements.

In contrast, increased visual complexity as in alphabetic letters or the double-barreled stimuli of Experiment 2 would be predicted to give high extroversion scorers an advantage, and this is exactly the result we obtained. In Experiment 2, in conjunction search, extroverted women and to some degree also men needed less time to find a target than more introverted personalities who searched for longer, with RTs above 2,250 ms. Thus, introversion produced the predicted long RTs in visual search. This result confirmed Hypothesis 1 that extroversion and openness would enhance engagement with the target as we found a facilitating effect in the most challenging conjunction search when the target was absent. Extroversion is associated with the seclusion level of the space that people prefer, that is, introverts prefer secluded spaces and extroverts prefer open spaces (Oishi \& Choi, 2020 online first). Thus, outgoing extroverts may quickly gain an overview in a visual array. Moreover, extroversion along with conscientiousness also shows significant correlations with executive control as indicated by distracter inhibition in Posner's attentional network task (Matthews \& Zeidner, 2012).

In Experiment 3 when visual stimulus complexity was highly varied and unpredictable, accuracy was halved but the latencies did not become longer. Stimulus repetition (Pollmann et al., 2016) and homogeneity (Nowakowska et al., 2017) provide more certainty that contributes to visual search, but this was intentionally avoided in Experiment 3. Personality variables did not bear upon this drastically reduced accuracy. Instead, again RTs showed an impact of personality factors. We mentioned already in the paragraphs above that neuroticism in men and women shortened RTs in visual search with simple and clear visual stimuli that were also contained in Experiment 3.

Moreover, in Experiment 3, being agreeable had an effect on RTs. Hypothesis 3 predicted that participants high in conscientiousness would be able to maintain their speed in the face of increasing task difficulty because of an aim to do well. However, instead, an effect of agreeableness showed in conjunction search when the target was absent. But because no significant effect for the dichotomized variable was obtained, it is concluded that the effect was rather subtle and could not be allocated to distinct personality trait but rather to a more general attitude.

In short, complex stimuli seem to render different relevant sex-specific traits than simple stimuli. Simple stimuli seem to encourage men with autistic traits as well as both men and women with high neuroticism scores to fast RTs. In contrast, finding a target among visually more complex stimuli which are more alike to letters was facilitated by extroversion. A limitation of the study is that we did not have an independent measure of visual acuity as it did not fall within the scope of our hypothesizing.

The long RTs predicted for target absent trials (Shahar et al., 2014; Thorpe et al., 1996) were found as agreeableness and conscientiousness in women were responsible for such long latencies. A US study with $N=320,128$ participants showed that the base rate of agreeableness in women is higher than in men throughout the life span (Kajonius \& Johnson, 2018) because of increased altruism. In a UK study with $N=30,033$ respondents, greater empathic concern and agreeableness was associated with the female gender, non-White ethnicity, having more education, and working in health, social care, or childcare professions (Sommerlad et al., 2020). Thus, that the present study with a UK sample recruited some of the female participants from within the social sciences could have been a limitation to its generalizability. Women who work in different professional areas may show a different personality structure. Nevertheless, we could also find differences between more or less conscientious women in the current sample. The extended RTs in target-absent trials in conjunction search in participants with personality traits that were added to the classic personality traits neuroticism and extroversion thus appear to be a reliable and relevant result to explain long RT tails in visual search.

\section{Conclusion}

So far, personality traits have rarely been in the focus of visual search research. Other visuospatial tasks such as mental rotation, however, have been extensively investigated for individual differences (e.g., Hegarty, 2018; Heil et al., 2018; Lauer et al., 2019). Our expectation that there would be sex-specific personality differences in visual search was a reasonable assumption that could be backed up by previous research. The long RT tail RT effect in visual search of the accelerating "less social" AQ score was specific to men, while those of the "more social" 
decelerating BFI factors agreeableness and conscientiousness were specific to women. However, the decisionmaking facilitating personality factors central to stimulus visual complexity were neuroticism for singletons and extroversion for double-barreled items, and these effects were similar for both sexes. Thus, sex-specific personality traits could explain decision-making thresholds, and visual stimulus complexity yielded an impact of the classic personality traits. Moreover, we showed that a large portion of the psychological process for accurate visual search requires predictability of item visual complexity. These are important results for one of the most wellresearched task paradigm in visual cognition.

\section{Electronic Supplementary Material}

The electronic supplementary material is available with the online version of the article at https://doi.org/10. 1027/1618-3169/a000520

ESM 1. Group means per experiment and condition $(N=65)$.

\section{References}

Al-Samarraie, H., Eldenfria, A., \& Dawoud, H. (2017). The impact of personality traits on users' information-seeking behavior. Information Processing \& Management, 53(1), 237-247. https:// doi.org/10.1016/J.Ipm.2016.08.004

Al-Samarraie, H., Sarsam, S. M., Alzahrani, A. I., \& Alalwan, N. (2018). Personality and individual differences: The potential of using preferences for visual stimuli to predict the Big five traits. Cognition, Technology \& Work, 20(3), 337-349. https://doi.org/10. 1007/S10111-018-0470-6

Alvarez, G. A., \& Cavanagh, P. (2004). The capacity of visual shortterm memory is set both by visual information load and by number of objects. Psychological Science, 15(2), 106-111. https:// doi.org/10.1111/J.0963-7214.2004.01502006.X

Baron-Cohen, S., Wheelwright, S., Skinner, R., Martin, J., \& Clubley, E. (2001). The autism-spectrum quotient (AQ): Evidence from Asperger syndrome/high-functioning autism, males and females, scientists and mathematicians. Journal of Autism and Developmental Disorders, 31(1), 5-17. https://doi.org/10.1023/A: 1005653411471

Battle, L., Crouser, R. J., Nakeshimana, A., Montoly, A., Chang, R., \& Stonebraker, M. (2020). The role of latency and task complexity in predicting visual search behavior. IEEE Transactions on Visualization and Computer Graphics, 26(1), 1246-1255. https://doi. org/10.1109/Tvcg.2019.2934556

Beringer, J., Wandmacher, J., \& Görtelmeyer, R. (1988). Age-related automatic versus controlled visual search. In I. Hindmarch, B. Aufdembrinke, H. Ott, I. Hindmarch, B. Aufdembrinke, \& H. Ott (Eds.), Psychopharmacology and reaction time (pp. 51-64). John Wiley \& Sons.

Bertrand, C., \& Thullier, F. (2009). Effects of player position and task complexity in visual exploration behavior in soccer.
International Journal of Sport Psychology, 40(2), 306-323, https://www.Cabdirect.Org/Cabdirect/Abstract/20093201538

Biggs, A. T., Clark, K., \& Mitroff, S. R. (2017). Who should be searching? Differences in personality can affect visual search accuracy. Personality and Individual Differences, 116, 353-358. https://doi.org/10.1016/J.Paid.2017.04.045

Biggs, A. T., \& Mitroff, S. R. (2014). Different predictors of multipletarget search accuracy between nonprofessional and professional visual searchers. The Quarterly Journal of Experimental Psychology, 67(7), 1335-1348. https://doi.org/10.1080/17470218. 2013.859715

Brandner, C. (2007). Strategy selection during exploratory behavior: Sex differences. Judgment and Decision Making, 2(5), 326-332, http://Journal.Sjdm.Org/Vol2.5.Htm

Broadbent, J., Galic, I., \& Stokes, M. A. (2013). Validation of Autism Spectrum Quotient adult version in an Australian sample. Autism Research and Treatment, 7, Article 984205. https://doi.org/ $10.1155 / 2013 / 984205$

Chan, A. H. S., \& Courtney, A. J. (1996). Foveal acuity, peripheral acuity and search performance: A review. International Journal of Industrial Ergonomics, 18(2), 113-119. https://doi.org/10.1016/ 0169-8141(95)00073-9

Chun, M. M., \& Wolfe, J. M. (1996). Just say no: How are visual searches terminated when there is no target present? Cognitive Psychology, 30(1), 39-78. https://doi.org/10.1006/Cogp.1996. 0002

Coan, R. W. (1972). Measurable components of openness to experience. Journal of Consulting and Clinical Psychology, 39(2), 346. https://doi.org/10.1037/H0033385

Costa, P. T., \& McCrae, R. R. (1992). NEO Pi-R Professional Manual. Psychological Assessment Resources.

Costa, P. T., \& McCrae, R. R. (2008). The revised Neo Personality Inventory (Neo-Pi-R). In G. J. Boyle, G. Matthews, \& D. H. Saklofske (Eds.), The Sage handbook of personality theory and assessment (vol. 2). Personality measurement and testing (pp. 179-198). Sage.

De Martino, B., Harrison, N. A., Knafo, S., Bird, G., \& Dolan, R. J. (2008). Explaining enhanced logical consistency during decision making in autism. Journal of Neuroscience, 28(42), 10746-10750. https://doi.org/10.1037/Neu0000016

Dhinakaran, J., De Vos, M., Thorne, J. D., \& Kranczioch, C. (2014). Neuroticism focuses attention: Evidence from SSVEPs. Experimental Brain Research, 232(6), 1895-1903. https://doi.org/10. 1007/S00221-014-3881-5

Donnelly, N., Hadwin, J. A., Menneer, T., \& Richards, H. J. (2010). The use of visual search paradigms to understand attentional biases in childhood anxiety. In J. A. Hadwin \& A. P. Field (Eds.), Information processing biases and anxiety: A developmental perspective (pp. 109-127). Wiley-Blackwell.

Endsley, M. R., \& Garland, D. J. (2000). Situation Awareness Analysis and Measurement. CRC Press.

English, M. C. W., Maybery, M. T., \& Visser, T. A. W. (2021). Magnitude of sex differences in visual search varies with target eccentricity. Psychonomic Bulletin \& Review, 28(1), 178-188. https:// doi.org/10.3758/S13423-020-01796-7

Eysenck, H. J., \& Eysenck, S. B. G. (1975). Manual of the Eysenck Personality Questionnaire. Edits.

Eysenck, H. J. (1970). Readings in Extraversion-Introversion. V. 2 Fields of Application. Staples.

Farmer, G. D., Baron-Cohen, S., \& Skylark, W. J. (2017). People with Autism Spectrum conditions make more consistent decisions. Psychological Science, 28(8), 1067-1076. https://doi.org/10.1177/ 0956797617694867

Flehmig, H. C., Steinborn, M. B., Westhoff, K., \& Langner, R. (2010). Neuroticism and speed-accuracy tradeoff in self-paced speeded mental addition and comparison. Journal of 
Individual Differences, 31(3), 130-137. https://doi.org/10.1027/ 1614-0001/A000021

Gurven, M., Von Rueden, C., Massenkoff, M., Kaplan, H., \& Lero Vie, M. (2013). How universal is the Big Five? Testing the five-factor model of personality variation among foragerfarmers in the Bolivian Amazon. Journal of Personality and Social Psychology, 104(2), 354-370. https://doi.org/10. 1037/A0030841

Hamby, T., Taylor, W., Snowden, A. K., \& Peterson, R. A. (2016). A meta-analysis of the reliability of free and for-pay Big five scales. The Journal of Psychology, 150(4), 422-430. https://doi.org/10. 1080/00223980.2015.1060186

Hegarty, M. (2018). Ability and sex differences in spatial thinking: What does the mental rotation test really measure? Pychometric Bulletin and Review, 25(3), 1212-1219. https://doi.org/10.3758/ S13423-017-1347-Z

Heil, M., Krüger, M., Krist, H., Johnson, S. P., \& Moore, D. S. (2018). Adults' sex difference in a dynamic mental rotation task. Journal of Individual Differences, 39(1), 48-52. https://doi.org/10.1027/ 1614-0001/A000248

Hogeboom, M., \& Van Leeuwen, C. (1997). Visual search strategy and perceptual organization covary with individual preference and structural complexity. Acta Psychologica, 95(2), 141-164. https://doi.org/10.1016/S0001-6918(96)00049-2

John, O. P., Donahue, E. M., \& Kentle, R. L. (1991). Big Five Inventory (BFI) [Database record]. APA PsycTests. https://doi. org/10.1037/t07550-000

Jonason, P. K., Koehn, M. A., Okan, C., \& O'connor, P. J. (2018). The role of personality in individual differences in yearly earnings. Personality and Individual Differences, 121, 170-172. https://doi. org/10.1016/J.Paid.2017.09.038

Juni, M. Z., \& Eckstein, M. P. (2017). The wisdom of crowds for visual search. Proceedings of the National Academy of Sciences, 114(21), E4306. https://doi.org/10.1073/Pnas.1610732114

Kajonius, P. J., \& Johnson, J. (2018). Sex differences in 30 facets of the five factor model of personality in the large public $(\mathrm{N}=320,128)$. Personality and Individual Differences, 129 , 126-130. https://doi.org/10.1016/J.Paid.2018.03.026

Kiss, M., \& Eimer, M. (2011). Attentional capture by size singletons is determined by top-down search goals. Psychophysiology, 48(6), 784-787. https://doi.org/10.1111/J.1469-8986.2010.01145.X

Krajbich, I., Bartling, B., Hare, T., \& Fehr, E. (2015). Rethinking fast and slow based on a critique of reaction-time reverse inference. Nature Communications, 6(1), 7455. https://doi.org/10.1038/ Ncomms8455

Lange-Küttner, C., \& Bosco, G. (2016). On being in the wrong place: The role of children's concepts and ballgame experience when judging a football player's offside position. International Journal of Developmental Science, 10(1-2), 73-84. https://doi.org/10. 3233/Dev-160185

Lange-Küttner, C., \& A.A., Puiu (2021). Data for “Perceptual load and sex-specific personality traits: The impact of the Big Five personality dimensions and autism quotient on visua search". https://osf.io/ktud6/.

Lange-Küttner, C., Korte, M. A., \& Stamouli, C. (2019). Parents' autistic personality traits and sex-biased family ratio determine the amount of technical toy choice. Frontiers in Psychology, 10, 2101. https://doi.org/10.3389/Fpsyg.2019.02101

Larson, L. M., Rottinghaus, P. J., \& Borgen, F. H. (2002). Metaanalyses of Big Six interests and Big Five personality factors. Journal of Vocational Behavior, 61(2), 217-239. https://doi.org/ 10.1006/Jvbe.2001.1854

Lauer, J. E., Yhang, E., \& Lourenco, S. F. (2019). The development of gender differences in spatial reasoning: A meta-analytic review. Psychological Bulletin, 145(6), 537-565. https://doi.org/10.1037/ Bul0000191
Lavie, N. (1995). Perceptual load as a necessary condition for selective attention. Journal of Experimental Psychology: Human Perception and Performance, 21(3), 451-468. https://doi.org/10. 1037/0096-1523.21.3.451

Lynn, S. K., \& Barrett, L. F. (2014). “Utilizing” signal detection theory. Psychological Science, 25(9), 1663-1673. https://doi.org/10.1177/ 0956797614541991

Matthews, G., \& Zeidner, M. (2012). Individual differences in attentional networks: Trait and state correlates of the ANT. Personality and Individual Differences, 53(5), 574-579. https:// doi.org/10.1016/J.Paid.2012.04.034

McCrae, R. R. (1987). Creativity, divergent thinking, and openness to experience. Journal of Personality and Social Psychology, 52(6), 1258-1265. https://doi.org/10.1037/0022-3514.52.6.1258

Nêcka, E., \& Szymura, B. (2001). Who has the temperament to attend? Neuroticism, extraversion, and the mechanisms of attention. Polish Psychological Bulletin, 32(3), 159-166

Newton, T., Slade, P., Butler, N., \& Murphy, P. (1992). Personality and performance on a simple visual search task. Personality and Individual Differences, 13(3), 381-382. https://doi.org/10.1016/ 0191-8869(92)90119-A

Nowakowska, A., Clarke, A. D. F., \& Hunt, A. R. (2017). Human visual search behaviour is far from ideal. Proceedings of the Royal Society B: Biological Sciences, 284(1849), Article 20162767. https://doi.org/10.1098/Rspb.2016.2767

Oishi, S., \& Choi, H. (2020). Personality and space: Introversion and seclusion. Journal of Research in Personality, 85, 103933. https://doi.org/10.1016/J.Jrp.2020.103933

O'Riordan, M. A. (2004). Superior visual search in adults with autism. Autism, 8(3), 229-248. https://doi.org/10.1177/1362361304045219

Palmer, S. E., Schloss, K. B., \& Sammartino, J. (2013). Visual aesthetics and human preference. Annual Review of Psychology, 64(1), 77-107. https://doi.org/10.1146/Annurev-Psych120710-100504

Peltier, C., \& Becker, M. W. (2017). Individual differences predict low prevalence visual search performance. Cognitive Research: Principles and Implications, 2(1), 5-11. https://doi.org/10.1186/ S41235-016-0042-3

Peterson, M. S., Kramer, A. F., Wang, R. F., Irwin, D. E., \& Mccarley, J. S. (2001). Visual search has memory. Psychological Science, 12(4), 287-292. https://doi.org/10.1111/1467-9280.00353

Plude, D. J., Hoyer, W. J., \& Lazar, J. (1982). Age, response complexity, and target consistency in visual search. Experimental Aging Research, 8(2), 99-102. https://doi.org/10.1080/ 03610738208258404

Pollmann, S., Eštočinová, J., Sommer, S., Chelazzi, L., \& Zinke, W. (2016). Neural structures involved in visual search guidance by reward-enhanced contextual cueing of the target location. Neuroimage, 124(pt A), 887-897. https://doi.org/10.1016/J. Neuroimage.2015.09.040

Remington, A. M., Swettenham, J. G., \& Lavie, N. (2012). Lightening the load: Perceptual load impairs visual detection in typical adults but not in autism. Journal of Abnormal Psychology, 121(2), 544-551. https://doi.org/M4 - Citavi

Ruzich, E., Allison, C., Smith, P., Watson, P., Auyeung, B., Ring, H., \& Baron-Cohen, S. (2015). Measuring autistic traits in the general population: A systematic review of the autism-spectrum quotient (AQ) in a nonclinical population sample of 6,900 typical adult males and females. Molecular Autism, 6(1), Article Number 2. https://doi.org/10.1186/2040-2392-6-2

Shahar, N., Teodorescu, A. R., Usher, M., Pereg, M., \& Meiran, N. (2014). Selective influence of working memory load on exceptionally slow reaction times. Journal of Experimental Psychology: General, 143(5), 1837-1860. https://doi.org/10.1037/A0037190

Sommerlad, A., Huntley, J., Livingston, G., Rankin, K. P., \& Fancourt, D. (2020). Empathy and its Associations With Sociodemographic 
and Personality Characteristics in a Large UK Population Sample. Psyarxiv. https://doi.org/10.31234/Osf.lo/Dgnkz

South, M., Chamberlain, P. D., Wigham, S., Newton, T., Le Couteur, A., Mcconachie, H., Gray, L., Freeston, M., Parr, J., Kirwan, C. B., \& Rodgers, J. (2014). Enhanced decision making and risk avoidance in high-functioning autism Spectrum disorder. Neuropsychology, 28(2), 222-228. https://doi.org/10.1037/ Neu0000016

Thorpe, S., Fize, D., \& Marlot, C. (1996). Speed of processing in the human visual system. Nature, 381(6582), 520-522. https://doi. org/10.1038/381520a0

Tom, A., \& Granié, M.-A. (2011). Gender differences in pedestrian rule compliance and visual search at signalized and unsignalized crossroads. Accident Analysis \& Prevention, 43(5), 1794-1801. https://doi.org/10.1016/J.Aap.2011.04.012

K. Wang \& W. Hou (Eds.), (2020) Research on interface complexity and operator fatigue in visual search task. Springer International Publishing.

Wang, M.-J. J., Lin, S.-C., \& Drury, C. G. (1997). Training for strategy in visual search. International Journal of Industrial Ergonomics, 20(2), 101-108. https://doi.org/10.1016/S01698141(96)00043-1

Weichselbaum, H., \& Ansorge, U. (2018). No suppression of stimulus-driven capture with distractor and target singletons of the same (color) dimension. Journal of Vision, 18(10), 457. https:// doi.org/10.1167/18.10.457

Weiss, A., \& Deary, I. J. (2019). A new look at neuroticism: Should we worry so much about worrying? Current Directions in Psychological Science, 29(1), 92-101. https://doi.org/10.1177/ 0963721419887184

Wolfe, J. M., Butcher, S. J., Lee, C., \& Hyle, M. (2003). Changing your mind: On the contributions of top-down and bottom-up guidance in visual search for feature singletons. Journal of Experimental Psychology: Human Perception and Performance, 29(2), 483-502. https://doi.org/10.1037/0096-1523.29.2.483

Wolfe, J. M. (1994). Guided search 2.0 A revised model of visual search. Psychnomic Bulletin \& Review, 1(2), 202-238. https://doi. org/10.3758/Bf03200774

Wolfe, J. M., \& Van Wert, M. J. (2010). Varying target prevalence reveals two dissociable decision criteria in visual search. Current Biology, 20(2), 121-124. https://doi.org/10.1016/J.Cub.2009.11.066

Woodbury-Smith, M. R., Robinson, J., Wheelwright, S., \& BaronCohen, S. (2005). Screening adults for Asperger syndrome using the AQ: A preliminary study of its diagnostic validity in clinical practice. Journal of Autism and Developmental Disorders, 35(3), 331-335. https://doi.org/10.1007/S10803-005-3300-7

\section{History}

Received December 2, 2020

Revision received July 15, 2021

Accepted July 18, 2021

Published online October 29, 2021

\section{Acknowledgments}

The study was presented on the TeaP 2021 at the University of UIm, Germany, ID 578.

\section{Publication Ethics}

The study was approved by the departmental ethics committee.

\section{Authorship}

The first and second authors jointly conceptualized the study, analyzed the data, and wrote the report. We are grateful to John Hucker who wrote the Visual Basic code available for download on the website of the Open Science Foundation https://osf.io/ug32h/. The study was conducted at the London Metropolitan University, UK, but both authors have since left the institution.

\section{Open Data}

To the best of my knowledge, I have provided all original materials and clear references to all other materials via a stable online repository (Lange-Küttner \& Puiu, 2021). The Visual Basic code is available for download on https://osf.io/ug32h/. My article contains no experiment with a pre-registration.

\section{Funding}

Open access publication enabled by Bremen University.

\section{ORCID}

Christiane Lange-Küttner

(D) https://orcid.org/0000-0001-6021-8931

\section{Christiane Lange-Küttner}

Department of Psychology

University of Bremen

Grazer Str. 2

28334 Bremen

Germany

c.langekuettner@uni-bremen.de;

c.langekuettner@outlook.com 